Privacy and

Advertising

Mail

Chris Jay Hoofnagle Jennifer M. Urban \& $\mathrm{Su} \mathrm{Li}$

Berkeley Center for

Law \& Technology

Berkeley Law 


\title{
Privacy and Advertising Mail
}

\author{
Chris Jay Hoofnagle, ${ }^{1}$ Jennifer M. Urban, ${ }^{2} \& \mathrm{Su} \mathrm{Li}{ }^{3}$ \\ Berkeley Consumer Privacy Survey \\ BCLT Research Paper4 \\ December 3, 2012
}

\section{Abstract}

In this paper, we consider why Americans may frame the generation and receipt of unsolicited advertising mail as a privacy violation. We then present data from our nationwide survey showing that a very large majority of Americans, across all ideologies, educational attainment levels, age, and income levels, support the creation of a do-not-mail mechanism similar to the popular Telemarketing Do Not Call Registry. We discuss our results in light of the fact that direct advertising mail now makes up more than half of all mailpieces sent by the United States Postal Service (USPS).

\footnotetext{
${ }^{1}$ Chris Jay Hoofnagle is a Lecturer in Residence at UC Berkeley Law and Senior Staff Attorney to the Samuelson Law, Technology \& Public Policy Clinic. Author Hoofnagle is a former director of Catalog Choice, which launched a free online mail preference service in 2007, in order to help individuals reduce the amount of unwanted advertising mail they received. The authors wish to thank Chuck Teller, the founder of Catalog Choice, for his help in assisting us research this issue.

2 Jennifer M. Urban is Assistant Clinical Professor of Law at UC Berkeley Law, and Director of the Samuelson Law, Technology \& Public Policy Clinic.

3 Dr. Su Li is Statistician of Empirical Legal Studies at UC Berkeley Law. 4 The underlying survey research for this paper was fully funded by Nokia, Inc. as part of an unrestricted research gift to the Berkeley Center for Law \& Technology.
} 


\section{Introduction}

Direct advertising mail has been in use in the United States since the $19^{\text {th }}$ century. 5 It is a longstanding tool for direct advertising to consumers, and source of revenue for the Postal Service.

According to the United States Postal Service (USPS), advertisers spent $\$ 171$ billion in 2010 advertising to consumers through the mail. ${ }^{6}$ According to the Direct Marketing Association (DMA), direct marketing through the mail (catalog and non-catalog) accounts for over $\$ 630$ billion in sales in 2011.7 As a percentage of all mail, advertising mail now represents over half of all mail sent through the USPS (see Figure 1). Direct advertising mail includes everything from catalogs and circulars sent directly to named consumers at identified addresses (often drawn from private-market profiles and mailing lists), to "saturation mail" sent to specific street addresses but addressed generically to "resident" or similar, to the recently-reinstated "patron mail" program, which allows advertising mail to be sent to all households without the need to identify specific addresses.

5 Richard B. Kielbowicz, Origins of the Junk-Mail Controversy: A Media Battle over Advertising and Postal Policy, 5(2) JOURNAL OF POLICY History 248, 253 (1993).

6 United States Postal Service, The Household Diary Study Mail USE \& ATTITUDES IN FY 2010 39, Apr. 2011, available at http://about.usps.com/current-initiatives/studying-americans-mailuse.htm (citing figures from the Magna Advertising Group).

7 Direct Marketing Association, Statistical Fact Book (2012). 
Figure 1: Starting in 2007, advertising mail volume comprised more than 50 percent of all mailpieces sent. ${ }^{8}$

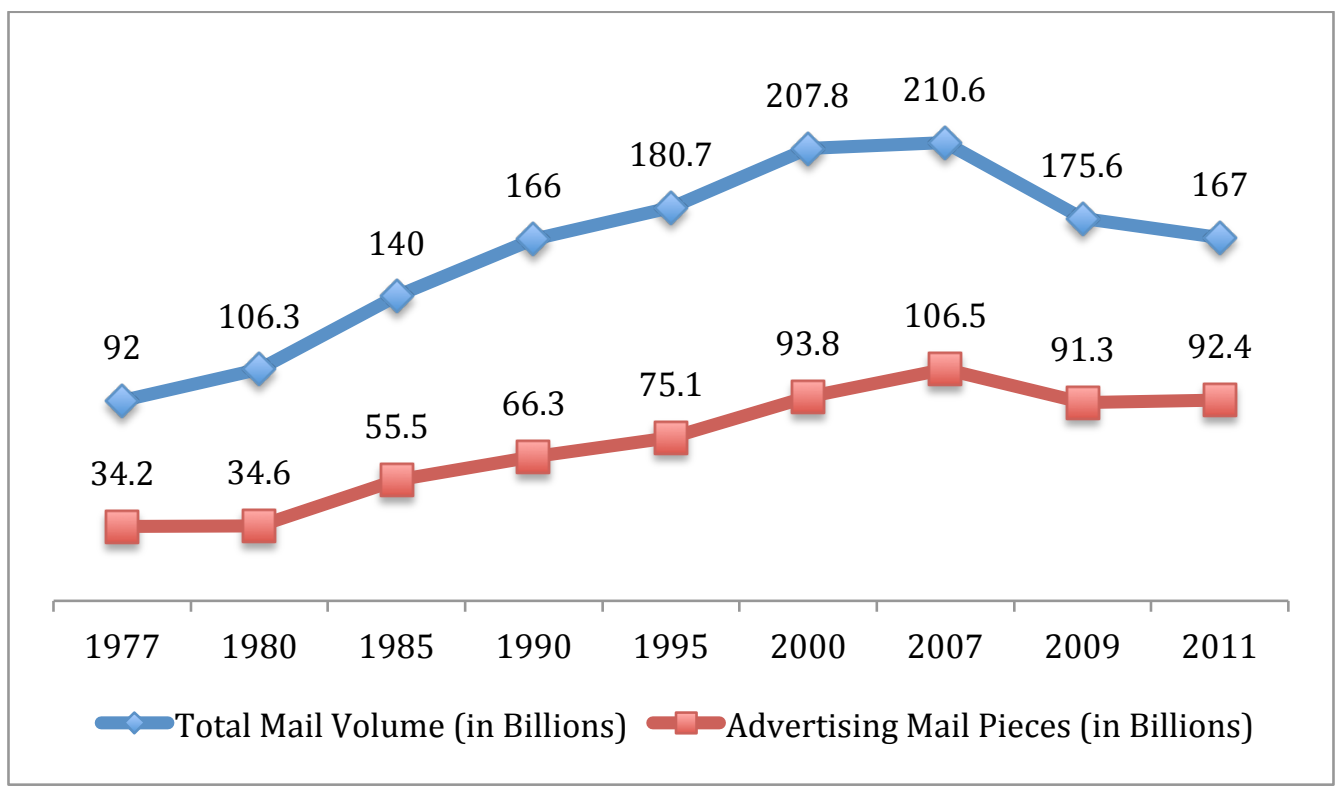

Americans receive a wide variety of advertising mail, including catalogs, fliers, and coupons. While receiving advertising mail is an everyday experience for many Americans, it has also long been considered a nuisance by some recipients. ${ }^{9}$ These attitudes have been supported, and perhaps fueled in part, by competitors. Newspaper publishers have long been at odds with mailers over advertising revenues, and newspapers, through editorial arms, popularized the term "junk mail" to disparage direct mail advertising. ${ }^{10}$

Over the years, consumers have lodged a variety of complaints about direct advertising mail, including concerns that it delayed the delivery of first-class and other desired

8 Compiled from Direct Marketing Association, 2010 Statistical FACT BOOK 39 (2010); DireCt MARKETING ASSOCIATION, 2012 STATISTICAL FACT BOOK 23 (2012).

9 Witness, for example, the complaints lodged against "patron mail" in the 1950s, which caused the USPS to suspend the program, reinstating it only in 2011. See infra notes 41-43 and accompanying text.

${ }^{10}$ Kielbowicz supra note 5 at 255. 
mail, ${ }^{11}$ and that the use of vast quantities of paper are ecologically harmful. ${ }^{12}$ The Direct Marketing Association, however, has carefully maintained the mail as a channel for advertising, in part by addressing some varieties of consumer concerns about receiving standard mail. As early as 1992, for example, the organization surveyed members on use of recycled paper, the use of which addresses some concerns about ecological impact. ${ }^{13}$ It has also tracked attitudes toward the receipt of unsolicited advertisements in the mail. ${ }^{14}$

In this paper, the fourth in our 2012-2013 Berkeley Consumer Privacy Survey series, ${ }^{15}$ we focus on another complaint commonly lodged against direct advertising mail: that it invades privacy. The concept of unwanted mail as a privacy violation is an interesting one. While it is a widespread understanding that unwanted advertising mail is perceived as causing a privacy harm, it is not necessarily obvious why this is so. We offer some reasons why unwanted mail may be perceived as privacy-invasive.

Next, we report survey findings that indicate that an overwhelming majority of respondents-across a wide swath of American demographic groups, including all ages, income groups, and political affiliations-strongly support an opt-out program for direct advertising mail similar to the Do Not Call list.

We discuss these findings in light of the importance of advertising mail as an industry, the financial challenges faced

\footnotetext{
${ }^{11}$ See infra notes 42 and 43 and accompanying text.

12 Ciara O'Rourke, Reducing the Junk-Mail Footprint, THE NEw YoRK Times, Mar. 16, 2009, available at http://green.blogs.nytimes.com/2009/o3/16/reducing-the-junk-mailfootprint/

13 Direct Marketing Association, Statistical Fact Book 84-90 (1992).

14 Direct Marketing Association, Statistical Fact Book 24-25 (1998).

15 Our reports from this series are available at:

http://www.law.berkeley.edu/privacysurvey.htm
} 
by the USPS, and the explosion in data profiling of consumers.

\section{Why Advertising Mail May Be Seen as a Privacy Problem}

"Privacy" is invoked in political debates to express a diffuse set of interests that are implicated by business, governmental, and interpersonal activity. These include concerns such as control over access to the self, personal security, reputation, false assumptions or conclusions being drawn based on personal information, the preservation of intimacy, and other issues. ${ }^{16}$ Invoking privacy in the context of advertising mail may seem misplaced at first. After all, such mailpieces can easily be discarded. Some may ask both, "what is the big deal?" and "why is this a privacy concern, specifically?"

We think there are at least two reasons why Americans may conceive of advertising mail as a kind of privacy issue. First, Americans may perceive the extensive data collection and aggregation activities that are integral to targeting advertising. Thus, they may conceive of advertising mail as a threat to a privacy interest in controlling personal data. Second, they may simply see advertising mail as intrusive, reflecting the privacy interest that is sometimes characterized as "access to the self."

\section{Privacy-Control and Advertising Mail}

Advertising mail implicates privacy interests described and critiqued as "privacy-control" by Professor Paul Schwartz. ${ }^{17}$ This is because generating, targeting, and sending advertising mail is connected to extensive collection and aggregation of data about recipients. Though advertising mail is sometimes

${ }^{16}$ Daniel J. Solove \& Paul M. Schwartz, Information Privacy LAW, $\left(4^{\text {th }}\right.$ ed. Aspen 2012).

17 Paul M. Schwartz, Privacy and Democracy in Cyberspace, 52 VAND.

L. REV. 1609, 1658-9 (1999). 
sent to named recipients at specific addresses, revealing that the sender has access to that information, Americans have almost no practical control over these activities. ${ }^{18}$ From where the personal information was obtained, and what the implications of a mailer's access to the data might be are not obvious and may be difficult or impossible to ascertain. The fact that there is such a lack of ready information about where advertising mail comes from could suggest that seeing mail as a "privacy" concern is a response to this opacity and lack of control; but it could also suggest that the issue is invisible to many Americans, and that their privacy concern is located elsewhere.

To get at this question, we searched previous studies to see if any helped clarify whether Americans see data collection and control as a source for "privacy" concerns in advertising mail. We found very little-in fact, only one-responsive study, suggesting the need for further research.

In this study, also the earliest public opinion poll on advertising mail that we could find, researchers asked Americans about information collection and tied information use to the generation of advertising mail. In a 1974 Harris poll, researchers asked, "Many people have been seriously concerned that their names and phone numbers are passed on from various sources without their permission. For each of the following actions, tell me if you personally would find it a serious violation, a minor violation, or no violation at all as far as your personal privacy is concerned?)...People using addresses from a phone directory to send you junk mail--that is, non-requested mail which tries to sell you a product or service." Forty-seven percent chose serious, 33 percent chose minor, and 17 percent said it was not a violation of privacy. ${ }^{19}$

\footnotetext{
${ }^{18}$ See discussion below concerning inadequacy of current advertising mail controls.

19 Harris Survey, Jun. 1974, Methodology: Conducted by Louis Harris \& Associates during June, 1974 and based on 1,512 personal interviews. Sample: National adult. [USHARRIS.071874.R1E].
} 
The Harris question suffers from bias. The question explicitly tells the respondent that other people are "seriously concerned" about privacy-control values in the generation of advertising mail from phone book directories. It also uses the term "junk mail," which is a form of question-begging that implies that all advertising mail is valueless. As such, the value of the responses to understanding a mail-related privacy concern is limited.

Nonetheless, the question may be instructive in two ways. First, the researchers explicitly connected a privacy-control interest with what presents itself as a de minimis intrusionthe receipt of some paper-in crafting their question. The fact that they chose to make this conclusion and present it in this way suggest that privacy-control was at least as salient an issue in 1974 as to prompt the researchers to assume that it was worth surveying respondents on. More directly, it is highly unlikely that all of the $80 \%$ of respondents who saw using phonebook addresses in this way answered thusly based only on the bias in the question. It thus illuminates, if weakly, that for some Americans, advertising mail represented a privacy-control problem.

Beyond direct survey research, we looked to court cases to see if advertising mail had been challenged based on privacycontrol arguments. And indeed, we found that some consumers have brought legal challenges to limit direct advertising mail that raise the idea of privacy-control. For instance, in Lamont $v$. Commissioner of Motor Vehicles, a New York resident challenged the sale of motor vehicle records to advertising mailers, arguing that the state compelling the revelation of truthful information that is then sold to other, unspecified companies, violates, "the right of privacy of the plaintiff and other registrants, and constitutes [sic] deprivation of their liberty and property under the First, 
Fourth, Fifth, Ninth and Fourteenth Amendments to the United States Constitution."20

However, courts have not been willing to recognize the broader objections to advertising mail based upon the privacy interests articulated in the Harris poll. The Lamont court viewed the objection as a mere trifle, and focused upon the intrusion rather than the data control issues pregnant in the case: "The mail box, however noxious its advertising contents often seem to judges as well as other people, is hardly the kind of enclave that requires constitutional defense to protect 'the privacies of life."'21 Similarly, in Shibley v. Time, plaintiffs objected to the generation and sale of mailing lists, but the court rejected the action, reasoning that lists did not result in some intrusion into a protected area. ${ }^{22}$

\section{Advertising Mail as an Intrusion}

As alluded to by the court in Shibley $v$. Time, privacyinfringing "intrusion" is a second reason why consumers may frame advertising mail as a privacy issue. Under the legal

20 The court characterized Lamont's claim as follows: "that plaintiff and others like him are compelled to register their motor vehicles with the Commissioner; that defendant Polk, having acquired the registration records, uses the names itself, or sells or leases the lists to others, 'for the solicitation through the mails, by telephone and in person, of the registered owners of vehicles, for the purchase of merchandise;' and that the result has been 'considerable annoyance, inconvenience and damage to the plaintiff and other registrants by reason of the large volume of advertising and crank mail and other solicitation to which they are subjected."' 269 F. Supp. 880 (S.D.N.Y. 1967).

${ }^{21} I d$. at 883 . We note that this practice was subjected to opt out requirements, and the to an affirmative consent provision in 1988. 22 "The right of privacy does not extend to the mailbox and therefore it is constitutionally permissible to sell subscription lists to direct mail advertisers. It necessarily follows that the practice complained of here does not constitute an invasion of privacy even if appellants' unsupported assertion that this amounts to the sale of 'personality profiles' is taken as true because these profiles are only used to determine what type of advertisement is to be sent." 45 Ohio App.2d 69 (Ohio Ct. App. 1975). 
typology of privacy interests devised by Professor Daniel Solove, this interest may be described as "limited access to the self." 23 While one reason Americans see unwanted mail as a privacy issue may be because they connect the receipt of advertising mail with database activities, they may also see advertising mail as intrusive in this way.

Indeed, many anti-marketing laws are driven by frustration with small but aggregated externalities from advertising practices. Regulations of spam and telemarketing were both triggered by the effects of many advertisers sending emails and initiating many phone calls to consumers. A single phone call may seem to be a trifle, but in aggregate, telemarketing became a major consumer frustration.

Here, our review of research yielded more results. A number of surveys have explored advertising mail from the perspective of limiting access to the self, and this research generally has found that Americans think advertising mail is intrusive. In June 2003, the Pew Internet \& American Life Project asked whether "...junk mail delivered by the postal service" is "a very big intrusion, a big intrusion, a small intrusion, or no intrusion at all?" Nineteen percent said it was a very big intrusion, 33 percent said that it was a big intrusion, 29 percent said it was a small intrusion, and 17 percent said no intrusion at all. ${ }^{24}$

As with the studies described above in our discussion of privacy control, this question suffers from bias problems by using the term "intrusion" throughout the choices, limiting its explanatory power. Unfortunately, we know of no studies that attempt to establish a sense of intrusion in a less direct

\footnotetext{
23 Daniel J. Solove, Conceptualizing Privacy, 90 CAL. L. REV. 1087 (2002).

24 Pew Internet \& American Life Project, SPAm Survey, Jun. 2003, retrieved Sep-21-2012 from the iPOLL Databank, The Roper Center for Public Opinion Research, University of Connecticut, available at http://www.ropercenter.uconn.edu/data_access/ipoll/ipoll.html
} 
manner. As with the privacy control studies, we note that the researchers' assumption that "intrusion" could be an issue could provide some limited evidence of its salience as a concept. In any case, when asked directly about mail as an "intrusion," the large majority of respondents saw at least some relevance in the description.

Similarly, in July 2000, USA Weekend Magazine found that 60 percent of respondents considered "junk mail" to be an invasion of privacy. ${ }^{25}$ Respondents were given seven different marketing behaviors and technologies to assess for intrusiveness. Only telemarketing (75 percent) and internet tracking (65 percent) were identified as intrusive by more people than junk mail. Junk mail was identified as an invasion of privacy by more consumers than several other categories of activities and technologies, including: access to library and video rental records (59 percent), receipt of email spam (47 percent), red light cameras (35 percent), and caller ID (29 percent). We have not been able to find any detailed discussion of the methods behind this study, and so cannot assess its overall strength.

There is a small amount of less direct evidence in the literature of mail as an intrusion. In April 1999, a survey sponsored by the National Consumers League explored consumer attitudes on advertising mail. The survey researchers asked respondents to rate their irritation with a series of "everyday consumer occurrences" on a scale of 1 to 10, with 1 meaning that it did not bother the consumer at all and 10 meaning "completely fed up." When probed about "junk mail," 59 percent chose 10-completely fed up. The overall mean for the question was 8.2, indicating a high level of irritation with advertising mail. ${ }^{26}$

25 Jedediah Purdy, An Intimate invasion, USA WeEkEnd MagazIne, Jul. 2, 2000, available at

http://159.54.226.237/oo_issues/ooo702/ooo702privacy.html.

26 National Consumers League, Consumers And The 21St Century

SurveY, Apr. 1999, Conducted by Louis Harris \& Associates, April 22 - 
Finally, there is some evidence of a combination of both concepts of privacy harm in the literature. Policy historian Richard B. Kielbowicz quotes a 1917 magazine editorial, "A Plague of Circulars," which stated the problem in the following manner: "Mail solicitation of business by printed circular has become an intolerable annoyance, to which all are subjected whose addresses appear in the directory or the telephone books." ${ }^{27}$ This characterization of the problem includes both intrusion ("an intolerable annoyance") and privacy-control ("all ... whose addresses" are used) concerns. ${ }^{28}$

The USPS itself has also researched advertising mail, but it has focused upon how people interact with advertising mail. In its 2010 Household Diary Survey, the USPS reported, "Whether they wish to receive more or not, most households either read or at least scan their advertising mail...54 percent of households usually read their advertising mail, while an additional 27 percent scan their mail. ${ }^{29}$ One might conclude from this finding that most Americans spend their evenings dutifully reading 14 pieces of advertising mail per week..$^{\circ}$

May 3, 1999 and based on 1,006 telephone interviews. Sample: National adult. Additional sponsors were Ameritech, Wyeth-Ayerst

Pharmaceuticals, Shapiro Educational Fund.

[USHARRIS.99CONSM.R735A]

27 Kielbowicz, supra footnote 5, at 253.

${ }^{28}$ Kielbowicz notes that this is an unusually early (1917) instance of stated concerns about advertising mail, which generally did not show up in discourse until the newspapers began objecting to such mail in the 1950s. Id. at 254. It is perhaps unsurprising that a magazine launched the 1917 attack, given the competitive campaign that periodicals like newspapers launched against advertising mail. Id. at 254-255.

29 United States Postal Service, The Household Diary Study Mail UsE \& ATTITUDES IN FY 2010, Apr. 2011, available at http://about.usps.com/current-initiatives/studying-americans-mailuse.htm.

${ }^{30} \mathrm{Id}$. at 42 (reporting that the average household receives 13.7 pieces of advertising mail a week). 
Looking more closely challenges this idea, in two ways. First, in investigating consumer behavior when receiving advertising mail, the USPS gave respondents four options: "Usually read it," "Usually scan it," "Read some, don't read others," and "Usually don't read it." In order to conclude that most recipients read their advertising mail, the Postal Service combined the "Usually read it" (18.7 percent) and "Read some, don't read others" (35.2 percent) options. ${ }^{31}$ Both of these options are highly qualified-the first with the limiter "usually," and the second with "don't read others."

The USPS data do show that Americans treat mail differently based upon sender, with recipients more likely than not to read mail coming from a sender that they do business with. Reading rates are dramatically lower when mail hails from known or unknown senders that the recipient has no business relationship with. ${ }^{2}$

Second, it should be noted that the USPS' questions are ambiguous. It is not clear at all by what is meant by the answers "scan" or "read" the mail, and the questionnaire used by the Postal Service does not define the terms. Even the most annoyed advertising mail recipient must at least look at the piece in order to discern whether it is personal correspondence, a bill, or an ad. Humans intuitively read when they see text. And of course much advertising mail is decorated to look like a bill or other important matter, forcing one to interrogate the piece.

The survey instrument thus provides no guidance to the administrator or respondent on what "read" or "scan" means in this context. Read-either "usually read" or "read some" could simply mean that the consumer looks at the outside of the mail piece.

${ }^{31} \mathrm{Id}$. at Table A4-8.

${ }^{32}$ Id. at Table A3-17. 


\section{Berkeley Consumer Privacy Survey Results}

Overall, research into privacy and advertising mail is quite limited. In our Berkeley Consumer Privacy Survey research, we sought to briefly examine this question. We were interested in Americans' attitudes about advertising mail, but most specifically about whether they wanted to control receipt of it. We chose the "Do Not Mail" (DNM) concept to ask about this, as we were also directly interested in whether that would be a supported policy response to unwanted advertising mail.

\section{Methods}

The Berkeley Consumer Privacy Survey obtained telephone interviews with a nationally representative sample of 1,203 adult Internet users living in the continental United States. Telephone interviews were conducted by landline (678) and cell phone (525, including 235 without a landline phone). Overall, 6,906 working landlines and 8,688 working cell phones were dialed. The response rate for the landline samples was 16 percent. The response rate for the cellular samples was 14 percent. Statistical results were weighted to correct known demographic discrepancies.

The survey was conducted by Princeton Survey Research Associates International (PSRAI), and was fully funded by Nokia, Inc. as part of an unrestricted gift to the Berkeley Center for Law and Technology. The content of the survey was entirely composed by Berkeley Law's Chris Jay Hoofnagle \& Jennifer M. Urban. Interviews were done in English by Princeton Data Source from January 27-February 12 , 2012. Statistical results are weighted to correct known demographic discrepancies. The margin of sampling error for the complete set of weighted data is \pm 3.4 percentage points. 


\section{Results}

We asked, "Some people think there should be a system like the National Do Not Call list that would help reduce the amount of advertisements 33 you receive in your postal mailbox. Would you strongly support, support, oppose, or strongly oppose the creation of such a system?"

We avoided any mention of "privacy" as a value, in order to avoid biasing the question in favor of a connection between advertising mail and privacy. Our framing of the question could reflect a privacy interest in limited access to the self for respondents who perceive mail in this way. In a more limited manner, it could speak to privacy-control issues, as it queries respondents about a mechanism for removing themselves from a mailing list held by others. It does not, however, speak to the main privacy-control database issues raised by advertising mail. It is possible that respondents had developed a sense that the overall survey instrument was querying them on privacy issues, but as this was only the second question asked of them, that is less likely than for questions that came up later in the survey.

33 While advertising mail is popularly known as "junk mail," this term obviously has a negative connotation that could have biased the question, so we did not use the term to describe it in the question. 


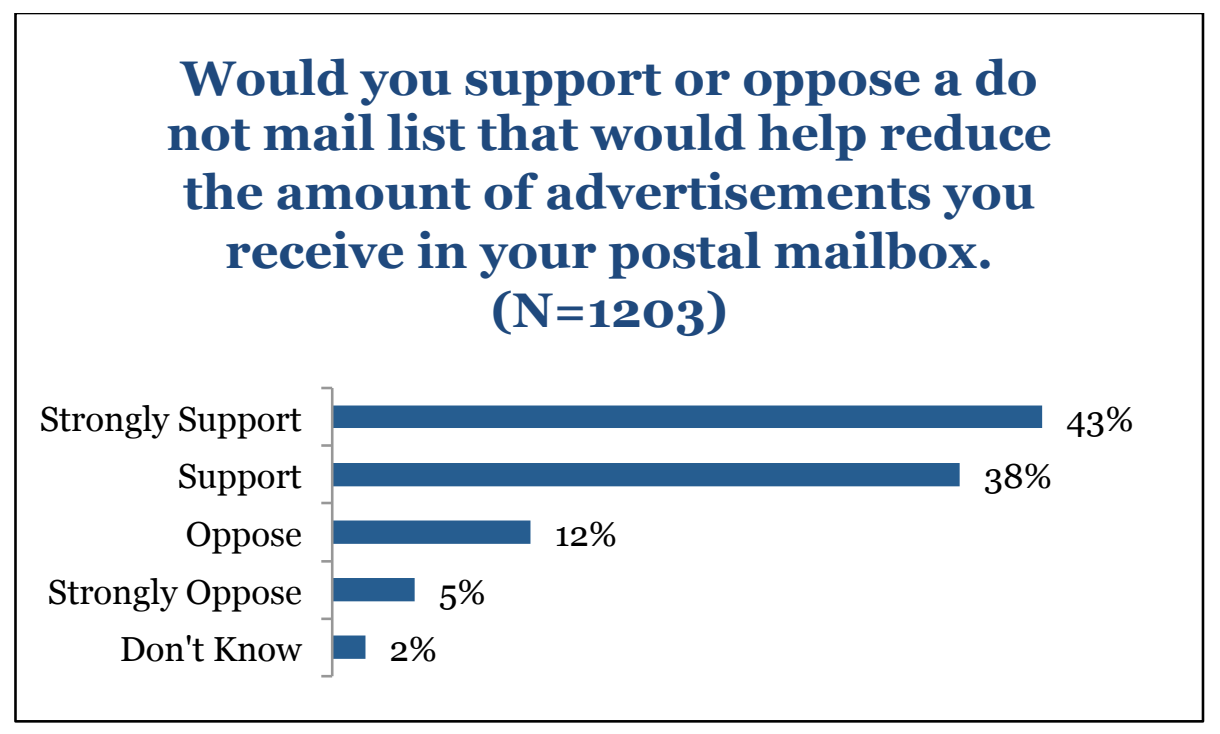

Perhaps unsurprisingly, we found that 81 percent support a DNM system (43 percent would "strongly support" a do-notmail system, and 38 percent would "support" it), and that only 17 percent would oppose or strongly oppose it.

Digging deeper, our survey shows that this support is not only very strong, it is very broad. We recoded the responses to a binary variable by combining the "strongly support" and "support" groups and the "oppose" and "strongly oppose" groups. When combined in this way, support for DNM remains constant across all income groups, all age groups, all educational levels, and across all ideologies (very conservative to very liberal).

All political affiliations express strong support for DNM, and there is no statistically significant difference among Democrats (who support DNM at 78.5 percent) and Republicans (who support DNM at 80.1 percent). Independents, however, are even more likely to support DNM (87.2 percent) than Democrats and Republicans, and this is statistically significant.

Both women and men overwhelmingly support DNM, but women support it significantly more than men (86 percent of 
women compared to 78 percent of men). ${ }^{34}$ Perhaps this difference is explained by the amount of standard mail women receive. Among one-person households, women receive more standard mail than men.35 Or perhaps women are more likely to sort mail in the household, and thus be confronted with the mail on a daily basis. Women might also be especially concerned about intrusion or privacy-control issues.

\section{Discussion}

Americans may conceive of advertising mail as a privacy problem, both because its generation requires extensive collection and use of information, and because receipt of mail can be an annoying intrusion. Few surveys have explored attitudes toward advertising mail, but those that have found that Americans think advertising mail is intrusive. Just one survey links junk mail to an underlying trade in personal information, finding that Americans are troubled by the use of publicly available data for mailing purposes. Our results contribute to the overall trend in showing that Americans broadly and strongly support an option to opt out of advertising mail.

This distaste for advertising mail, however, is offset by strong business reasons that contribute to the continuation and growth of advertising mail as a feature of the United States mail system.

34 This result remains after controlling for Independent status; similarly, the result that Independents support DNM significantly more than Republicans and Democrats remains after controlling for gender. 35 United States Postal Service, The Household Diary Study MaIL UsE \& ATTITUDES IN FY 2010 Table A3-9, Apr. 2011, available at http://about.usps.com/current-initiatives/studying-americans-mailuse.htm. Not all standard mail is advertising mail, however, it is often used as a proxy to distinguish between personal correspondence and business-related material. 
First are the fiscal challenges faced by the United States Postal Service. The USPS is an important American institution. ${ }^{36}$ It is relied upon by individuals and businesses alike as a trustworthy intermediary and service provider for important and sensitive correspondence. It provides not only economic security, but also physical security, as a reliable infrastructure for the government to distribute items to Americans in case of emergency.

In recent years, the USPS has suffered from great financial distress. ${ }^{77}$ The organization must maintain a high level of reliability, universal service, large mandated payments to retirees, and its current workforce, while mail volumes have dropped somewhat. It also faces competition from private delivery companies that are not subject to universal service requirements, and the USPS is legally restrained from aggressively competing with them..$^{8}$

In order to address these challenges, the USPS is increasing its reliance on direct advertising mail. 39 For instance, the Postal Regulatory Commission recently offered large discounts to coupon mailer Valassis under a special negotiated service agreement. Under the agreement, the USPS expects to raise between $\$ 4$ and $\$ 15$ million in revenue from the increased mail volume from Valassis. But for Valassis to enjoy discounts, it must increase the amount of mail it sends. 40

36 U.S. Constitution, Article I § 8.

37 R. Richard Geddes, Policy Watch: Reform of the U.S. Postal Service, 19 The Journal of ECONOMIC PersPectives 217 (Summer 2005), available at http://www.jstor.org/stable/4134981.

${ }^{38} 39$ USC $\S 3633$ (2012).

39 Ron Nixon, Seeking Revenue, Postal Service Plans to Deliver More Junk Mail, NEw York Times, Sept. 19, 2012, available at http://www.nytimes.com/2012/09/20/business/seeking-revenuepostal-service-plans-to-deliver-more-junk-mail.html. 40 Postal Regulatory Commission, Valassis NSA, Aug. 23, 2012, available at http://www.prc.gov/prcdocs/home/whatsnew/Valassis\%2oOrder_No_1448_2871.pdf 
The USPS' modern arrangement with Valassis reflects the longstanding tension between direct advertising mail and advertising in newspapers, with newspapers complaining that advertising revenue will be shifted to the mails instead of carried in newspaper circulars. ${ }^{41}$

Newspapers and direct mailers clashed most directly in the 1950s, after the USPS extended its "patron mail" program to all delivery routes. $4^{2}$ The patron mail program allowed marketers and others to deliver material to every household, without even providing a name or address. Advertisers delivered material in bulk to the post office, and carriers in turn delivered one mailpiece to every address. According to reporting in the New York Times, this program, "developed a countrywide protest from housewives, business houses and others who contended that while their mail boxes were being stuffed with 'junk mail,' the letters for which they were waiting were being delayed in delivery." 43 The then Post Office Department decided to stop the program. The Times also reported that mailing list brokers were delighted with the termination of the program, as the ability to deliver unaddressed mail reduced the need to purchase information about individuals 44

In 2011, after a 56-year hiatus, the USPS restarted the patron mail program, now called "Every Door Direct Mail."45 In addition, it has long operated a "saturation mail" service that allows advertisers to send mail to every door. This service

${ }^{41}$ Erik Sass, NAA Blasts USPS-Valassis Deal, Media Daily News, Aug. 23, 2012, available at http://www.mediapost.com/publications/article/181496/naa-blastsusps-valassis-deal.html.

$4^{2}$ Kielbowicz, supra note 5 at 254.

43 C. P. Trussell, Post Office to Stop 'Junk Mail' March 31, THE New York Times, Dec. 31, 1954.

44 Id.

45 United States Postal Service, Every Door Direct Mail - Retail and Every Door Direct Mail Program, n.d., available at http://faq.usps.com. 
requires that mail have a street address, but it may be addressed to "resident" or similar. It seems likely that these new programs will-far from limiting advertising mail, as apparently desired by consumers-increase advertising mail over and above the high proportion of mail that it already comprises. ${ }^{46}$

Further, as information society anxieties have captured the attention of regulators in the US, leading to the passage of several sector-specific laws regulating marketing practices, advertising mail has remained untouched. A variety of existing options for limiting advertising mail-sometimes explicitly and sometimes less clearly on privacy grounds-has been unavailing thus far.

First, a 1970 law does require the USPS to provide one choice mechanism - the "prohibitory order"-to mail recipients. 47 In Rowan v. United States Post Office Department, the Supreme Court upheld this statute, which allows individuals to obtain "prohibitory orders" against specific mailers. ${ }^{48}$ Although Prohibitory Orders were created to address "pandering advertisements," some Americans use prohibitory orders to stop all kinds of advertising mail. But the Prohibitory Order process is paper-based and labor intensive, requiring that the recipient open and send the mailpiece to a specific USPS office, and each Order only applies to a single mailer. Thus, it is not very useful for those attempting to address the privacy-control issues embedded in advertising mail.

Self-regulation on the part of advertising mailers is another option. The Direct Marketing Association has operated a selfregulatory opt out system since 1971, the "Mail Preference

\footnotetext{
46 As we noted in the introduction to this piece, advertising mail surpassed 50 percent of all mailpieces in 2007. See supra Figure 1 at page 3

4739 USC 3008 (2012); Pub.L. 91-375, Aug. 12, 1970, 84 Stat. 748.

48 397 U.S. 728 (1970).
} 
Service." But the DMA's mail system suffers from several inadequacies. As a threshold matter, not all marketers are members of the DMA, and thus not all are required to comply with DMA rules. In order to opt out, one must provider personal information to direct marketers, a mechanism with which mail recipients might be uncomfortable. Further, the system addresses the intrusion issue but not the underlying privacy issues associated with the collection and use of information. Finally, the DMA has structural incentive conflicts that could prevent the organization from aggressively representing consumer interests in the mail space, or at least prevent consumers from perceiving its selfregulatory mechanism as an availing one.

It is thus unsurprising that the DMA's program has not been very effective at limiting advertising mail. The DMA states that last year, the Mail Preference Service blocked 930 million mailpieces, 49 or about one percent (1\%) of all advertising mail.

These self-regulatory weaknesses have lead to a third option-the creation of Catalog Choice and other non-profit efforts to give individuals more control over mail.50 Often, these efforts have been motivated by ecological concerns, and by the externalities involved in disposing of unwanted advertising mail. Nonetheless, to date Catalog Choice has processed over 26 million opt-out requests on behalf of 1.5 million households with a four-person staff. It is not necessarily smooth sailing, however. The DMA reacted to Catalog Choice's entrance by advising mailers not to participate in the Catalog Choice program..$^{1}$

49 DMA, DMACHOICE FAQs (2012), available at https://www.dmachoice.org/dma/static/faq.jsp. 50 Catalog Choice, About Catalog Choice, n.d., available at https://www.catalogchoice.org/about; 41 Pounds, ABOUT Us, n.d., available at http://www.41pounds.org/about/.

${ }^{51}$ Ellen Keohane, Catalog opt-out programs spark debate, DIRECT MARKETING NEWS, Jun. 9, 2008, available at 
Self-regulatory efforts seem unlikely to be availing, given their current track record. The DMA has had over 40 years to implement an efficacious approach to concerns over advertising mail, yet its mail preference service blocks only about 1 percent of advertising mail. This is reminiscent of a similarly anemic intervention the group made for telemarketing - the DMA "Telephone Preference Service." It was established in 1985 and ended in light of the government-mandated Telemarketing Do-Not-Registry list. At its height in 2002, the DMA's self-regulatory choice system for telemarketing only had 4.5 million enrollments..$^{2}$

By contrast, the FTC Do-Not-Call Registry had 51 million enrollments in its first year of operation, and now has 217 million enrollments.53 This may suggest that a fourth option-regulatory intervention-is the most appropriate response to consumers' desire to limit advertising mail. There are complications for this option, as well, however, not least the effect widespread opt-outs might have on the USPS's fiscal situation, the need to look more closely at the economic importance of advertising mail, and the need to consider speech interests.

http://www.dmnews.com/catalog-opt-out-programs-sparkdebate/article/111053/

52 Comments of THe Direct Marketing Association, InC., AND the US CHAMBer of COMMERCE, TELEMARKETING RULEMAKING - AMENDMENTS to the Telemarketing Sales Rule, FTC File No. R411001, Apr. 15, 2002.

53 Federal Trade Commission, FTC Issues FY 2012 National Do Not CALl Registry Data BoOK, Oct. 16, 2012, available at http://www.ftc.gov/opa/2012/10/dncdatabook.shtm 


\section{Conclusion}

In considering why Americans may think of advertising mail as a "privacy" issue, we suggest that this may be both because of the extensive collection and use of personal information targeting and sending it entails, and a reaction to a sense of intrusion created by receiving unwanted mailpieces. There is a little more information in the literature and court cases on the concept of "intrusion" than the concept of "privacycontrol," but the literature is lean overall, and the concepts have never been compared to one another, so we cannot say if one is more salient than the other. Our data contribute to the overall trend by showing that most Americans would like to have some ability to block advertising mail. This result is robust across political ideology, educational attainment, age, and income level. Both men and women strongly support the idea of DNM, though women support it more.

Survey research showing annoyance with advertising mail and support for a do-not-mail mechanism does not in itself justify regulatory action. Nor does it specify how DNM should be implemented if it were adopted. Similarly, regulation of saturation and "Every Door Direct" mail may speak to Americans' interest in reducing intrusions into their home, but it would do little to address the interests in controlling the underlying collection and use of personal data.

Nonetheless, it would be reasonable to consider interventions in this space to respond to Americans' privacy concerns. Indeed, we think it would be reasonable to consider interventions, if not for privacy, then for the sake of the integrity of the USPS as one of America's great institutions. Especially in light of its fiscal constraints and lack of more broad-based support from Congress, the USPS sees advertising mailers as an important constituent and aggressively pitches new ways to get advertising mail into 
mailboxes.54 Over the years, it has failed to modernize the outdated and unwieldy Prohibitory Order process or create other innovations to help another main constituent-mail recipients-avoid unwanted mail.

The USPS' fiscal challenges have created incentives for the agency that directly contravene recipients' desire to manage advertising mail. Though only a limited number of studies exist, the strong thread among them is dislike for unwanted advertising mail; our results show a strong desire for opt-out control. The USPS' current course of increasing its reliance on advertising mail, while fiscally understandable, could cause all mail to simply become "junk" in the eyes of Americans. Americans who can abandon the USPS are more and more likely to in light of increasing advertising mail volumes.

Given the importance of advertising mail as an industry, and of the USPS to United States economic, security, and social interests, our findings could serve as a wake-up call to markets, the USPS, and regulators to more fully explore citizens' rejection of direct advertising mail and find ways to address their concerns while preserving the fundamental service provided by the USPS.

54 USPS searches for more advertising mail, DIRECT MARKETING NEWS, Jun. 1, 2011, available at http://www.dmnews.com/usps-searches-formore-advertising-mail/article/203563/. 


\section{Annex: The Dutch Approach to Saturation Mail5s}

In the Netherlands, individuals can opt out of unaddressed ("saturation") mail and

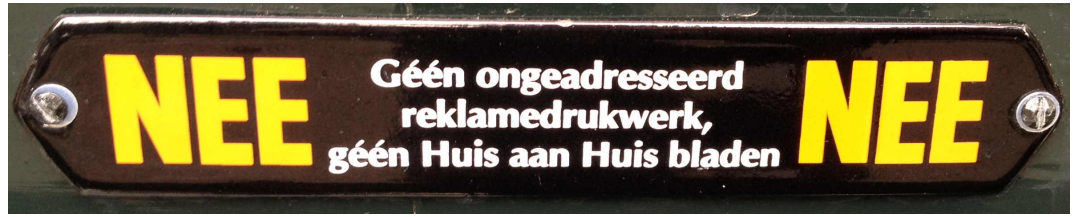
from free newspapers and circulars..$^{6}$ They do so by affixing a sticker on their mailbox that declares, "No unaddressed advertising and no house-tohouse newspapers." The system is self-regulatory, and was established in 1992 largely to address environmental concerns. As such, it does not address the problem of collection and use of personal data, in part because such concerns are addressed by existing data protection regulation.

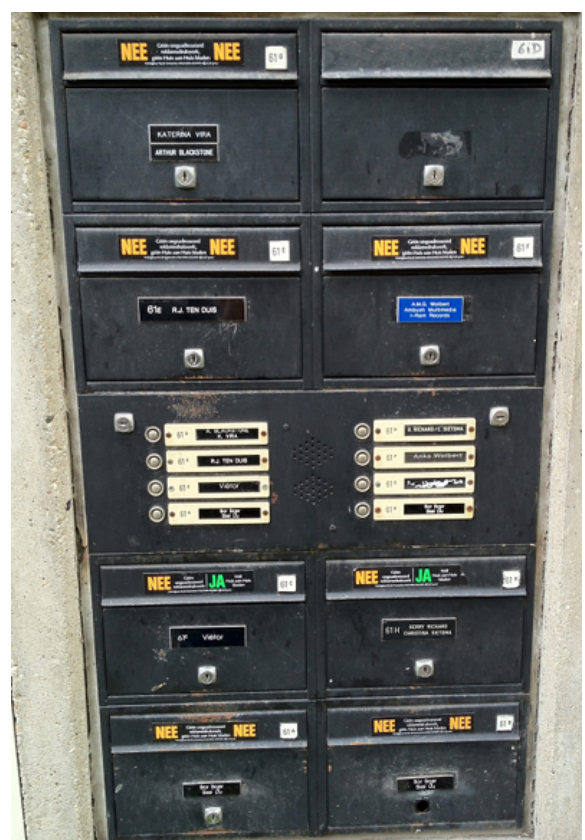

This approach has its complexities. Some people who share a mailbox disagree over receipt of mail, and people are known to create custom instructions for delivery of material.

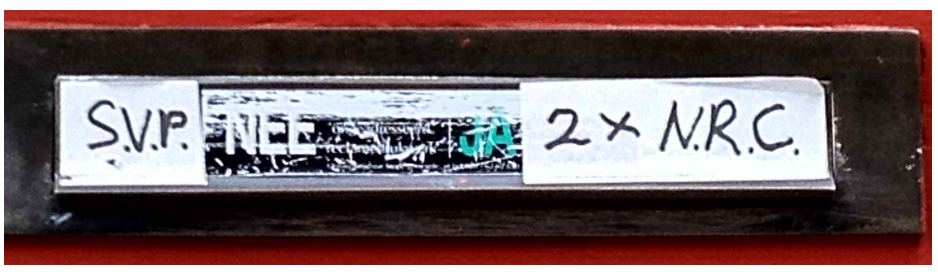

The opt out stickers are available from local government offices. They show that some people are willing to pay to avoid the intrusion of unwanted advertising. For instance, the top "Nee Nee" sign is enameled and sells for over €20, while others have had brass plates made.57 Some even buy "hip" junk mail stickers..$^{8}$ It is estimated that 17 percent of Dutch homes opt out. ${ }^{59}$

55 Many thanks to Professor Jaap-Henk Hoepman for helping us research this topic.

${ }^{6}$ Dutch Dialogue Marketing Association, Post, n.d., available at http://ddma.nl/juridisch-loket/dossiers/post/.

${ }^{57}$ See e.g. http://www.ja-nee-sticker.com/emaille-ja-nee-sticker.

${ }^{8}$ See e.g. http://www.muurstickerplaza.nl/Nee-nee-sticker-hi.

59 CEBUCO, RATIOS, n.d., available at http://www.cebuco.nl/dagbladen/kengetallen/ 